\title{
New Quinone Polyetherurethane Cationomers. Synthesis of Some Ionenes Based on Hydroquinone Diamine
}

\author{
Emil C. Buruiana and Tinca Buruiana \\ Romanian Academy, Institute of Macromolecular Chemistry "P. Poni" \\ Aleea GR. Ghica Voda 41 A, 6600-Iasi, Romania
}

(Received May 15, 2000; Accepted October 3, 2000)

\begin{abstract}
Polyetherurethane cationomers with hydroquinone groups in their main chains were synthesized by two-step Menschutkin reaction, using as partner 2,5-bis-( $N, N$-dimethylaminomethyl)-hydroquinone. All polycations were characterized by elemental and spectral analysis. The absorption spectra suggested that into ionomeric backbone a small content of disubstituted benzoquinone appeares as result of oxidation of the hydroquinone inserted initially. A preliminary study of $\mathrm{Fe}$ induced oxidation and reduction (by UV irradiation in the presence of isopropyl alcohol) indicated irreversible oxidation of hydroquinone structure in the aqueous media. In the polymeric films swelled in isopropyl alcohol and irradiated, the reduction of disubstituted benzoquinone at hydroquinone occurred. Some tensile and thermal properties of corresponding films showed values typical to elastomeric polyurethanes.
\end{abstract}

KEY WORDS Hydroquinone Polyetherurethane / Brom Ionene /

Polymers with redox active moieties have attracted strong interest for many years, and papers have been published on the synthesis and specific behavior. ${ }^{1}$ Quinone and hydroquinone are the most simple redox structures. The chemical properties of the polymers bearing these functional groups in the main chains as well as chemical interconversion have extensively been studied. ${ }^{2-4}$ Many quinone polymers have been prepared by dehalogenative polycondensation accompanied sometimes by chemical transformation that leads to polymers with hydroquinone and para-benzoquinone units in the backbone. $^{5}$ Yamamoto $^{6}$ reported the preparation of smooth film of poly(hydroquinone) by electrooxidative polymerization of hydroquinone and Dordick, ${ }^{7}$ obtained meta-bonded poly(hydroquinone) with interesting electrochemical response by multienzymic process. Studies on hydroquinone-polyesters have been actively pursued. ${ }^{8-10}$

Among currently investigated polymers, polyurethanes offer advantages such as easy synthesis, good optical quality thin films with elastomeric properties, long term stability and good solvent resistance. Despite a great deal of research effort on amine- quinone polyurethanes, developed primarily as corrosion inhibiting coatings, ${ }^{11-13}$ there are a few examples in the literature describing polyurethanes with hydroquinone groups in their main chains. ${ }^{14-16}$

Our program on the synthesis of new polyurethane ionomers with chromophoric functionality, ${ }^{17-19}$ has been directed towards insertion of quinone moieties into ionomeric architecture, which combine well-known properties of polyurethanes with those from co-existence of minority of ionic groups (usually $1 \mathrm{meq} \mathrm{g}^{-1}$ or less). ${ }^{20}$ Interesting applications of ionomers are generally related to ability to form aqueous dispersions in the absence of internal emulsifiers, widely utilized as films and coating materials. For such ionomers, the presence of certain functionality on polymeric chains, for further modifying properties, may have strong effect on the specific behavior of the polymers predestined for adhesive applications and whose qualities are not completely understood.

This paper describes the synthesis of a hydroquinone tertiary diamine and using this monomer as partner in a two-step Menschutkin reaction to prepare polyurethane cationomers of the ionene type. Some characteristics of hydroquinone diamine and corresponding polyetherurethane ionenes are presented.

\section{EXPERIMENTAL}

\section{Materials}

Poly(tetramethylene oxide) diols of various average molecular weights (BASF comp) were dried and degassed at $100-110^{\circ} \mathrm{C}$ and $1-2 \mathrm{mmHg}$ for $2 \mathrm{~h}$ prior utilization. 2,4'-Dibenzyldiisocyanate ${ }^{21}$ and 2,4-toluylene diisocyanate (2,4-:2,6-TDI / 80:20, Fluka comp.) were used freshly distilled. Dimethylformamide (DMF) and the solvents used in synthesis were dried over $5 \mathrm{~A}$ molecular sieves before use.

Synthesis of 2,5-bis-(N,N-dimethylaminomethyl)hydroquinone

A mixture based on a solution of hydroquinone $(0.25$ mol, $27.5 \mathrm{~g})$ dissolved in tetrahydrofurane $(100 \mathrm{~mL})$ and two aqueous solutions of dimethylamine $(0.74 \mathrm{~mol}, c=$ $28 \%)$ and paraformaldehyde $(0.25 \mathrm{~mol})$ respectively, was stirred and refluxed for $1 \mathrm{~h}$. To this solution, $1 \mathrm{~mL} \mathrm{HCl} \mathrm{(c}$ $=37 \%$ ) was added and then refluxed $2 \mathrm{~h}$. The solvents were removed by distillation and the remain product was purified by recrystallization from acetone. Yield $24 \mathrm{~g},(45 \%)$.

${ }^{1} \mathrm{H} \mathrm{NMR}\left(\mathrm{CDCl}_{3}\right):(\mathrm{ppm}) 6.5(2 \mathrm{H}, \mathrm{s}$, aromatic); 2.15 $\left(12 \mathrm{H}, \mathrm{s}, \mathrm{CH}_{3}-\mathrm{N}\right) ; 3.62\left(4 \mathrm{H}, \mathrm{s}, \mathrm{CH}_{2}-\mathrm{N}\right) ; 10.7(2 \mathrm{H}, \mathrm{s}$, $\mathrm{HO}-\mathrm{Ar}$ ). Calc. for $\mathrm{C}_{12} \mathrm{H}_{20} \mathrm{~N}_{2} \mathrm{O}_{2}: \mathrm{C}=64.28 ; \mathrm{H}=8.92 ; \mathrm{N}=$ 12.5 (\%). Found: $\mathrm{C}=64.22 ; \mathrm{H}=8.91 ; \mathrm{N}=12.42(\%)$.

\section{Ionene Synthesis}

The synthesis of the prepolymer with dimethylaminoend groups was carried out starting from poly(tetrametylene oxide) diol (PTMO) and 2,4'-dibenzyldiisocyanate 
(2,4 $\left.4^{\prime} \mathrm{DBDI}\right)$ or 2,4-toluylenediisocyanate (2,4-TDI:2,6TDI / 80:20). The reaction was performed with $0.01 \mathrm{~mol}$ dehydrated PTMO and $0.02 \mathrm{~mol}$ diisocyanate at $60^{\circ} \mathrm{C}$ for $16 \mathrm{~h}$ under purified nitrogen. The end of this reaction was monitored by IR spectroscopy, following the disappearance of the hydroxyl band of PTMO at $3480 \mathrm{~cm}^{-1}$. The prepolymer with isocyanate-end groups was reacted with $0.02 \mathrm{~mol} N, N^{\prime}$-dimethylaminoethanol at $60^{\circ} \mathrm{C}, 3 \mathrm{~h}$. The reaction was also verified by IR spectroscopy disappearance of the isocyanate band centered at $2260 \mathrm{~cm}^{-1}$. The reaction mixture was allowed to cool to room temperature and traces of $N, N^{\prime}$-dimethylaminoethanol were removed under reduced pressure. In a DMF solution of prepolymer with dimethylamino-end groups $(c=10 \mathrm{~g}$ $\mathrm{dL}^{-1}$ ), 0.02 mol 1,4-dibromobutane was added and Menschutkin reaction was performed at $60^{\circ} \mathrm{C}$ for $25 \mathrm{~h}$. The resulting polymer with bromoalkyl-end groups was extended by quaternization with $0.01 \mathrm{~mol} 2,5$-bis- $(N, N$ dimethylaminomethyl)-hydroquinone at $60^{\circ} \mathrm{C}$ for $35 \mathrm{~h}$ and thus the polyurethane ionene was synthesized. The cationic polyurethane was purified by precipitation from the DMF: $\mathrm{CH}_{3} \mathrm{OH}$ solution ( $4: 1 \mathrm{v} / \mathrm{v}$ ) with diethylether for $2-3$ times and drying at reduced pressure over $\mathrm{CaCl}_{2}$ for some days.

\section{Measurements}

The structures of intermediates and polymers were verified by ${ }^{1} \mathrm{H}$ NMR, IR and UV spectroscopy on JEOL$60 \mathrm{Mz}$, SPECORD-M 80 and SPECORD M 42 spectrophotometers. Transparent films for further testing were prepared by $\mathrm{DMF}: \mathrm{CH}_{3} \mathrm{OH}$ solution casting $(c=10 \mathrm{~g}$ $\mathrm{dL}^{-1}$ ) at $60^{\circ} \mathrm{C}$ on a Teflon plate. Films were allowed to dry at $50-55^{\circ} \mathrm{C}$ for $24 \mathrm{~h}$ and vacuum dried at $60^{\circ} \mathrm{C}$ for 48 $h$ in order to remove any residual solvent. Tensile properties of elastomeric ionenes were measured at room temperature on $0.2-0.4 \mathrm{~mm}$ film samples. Measurement was carried out using an universal testing machine Model 500. Thermal analysis was performed using a Perkin-Elmer differential scanning calorimeter. The polymers $(15 \pm 2 \mathrm{mg})$ were cooled to $-130^{\circ} \mathrm{C}$ and heated at a rate of $20^{\circ} \mathrm{C} \mathrm{min}{ }^{-1}$ up to $230^{\circ} \mathrm{C}$. Thermogravimetric analysis (TGA) at $40-400^{\circ} \mathrm{C}$ was done using a Derivatograph MOM (Budapest) at a heating rate of $12^{\circ} \mathrm{C}$ $\min ^{-1}$ under nitrogen purging. The weight of each sample was $5 \mathrm{mg}$.

\section{RESULTS AND DISCUSSION}

\section{Monomer Synthesis}

The synthetic route for the hydroquinone diamine (HQ-D) is based on Mannich reaction between hydroquinone, formic aldehyde and dimethylamine (Scheme 1). The structure of tertiary diamine, as a white crystalline product, was followed by spectral methods and elemental analysis. ${ }^{1} \mathrm{H}$ NMR spectrum for HQ-D showed several peaks: two singlets, one at $6.5 \mathrm{ppm}$ and one at $10.7 \mathrm{ppm}$, assigned to the aromatic and hydroxyl protons respectively, of the hydroquinone derivative, one singlet at 2.5 ppm, attributed to the aliphatic protons $\left(\mathrm{CH}_{3}-\mathrm{N}\right)$ and other singlet at $3.62 \mathrm{ppm}$, which is characteristic of $\mathrm{Ar}-\mathrm{CH}_{2}-\mathrm{N}$. Integration for hydroxyl groups $(2 \mathrm{H})$ and aromatic protons $(2 \mathrm{H})$ confirmed the formation of the prescribed hydroquinone diamine. In the electronic ab-

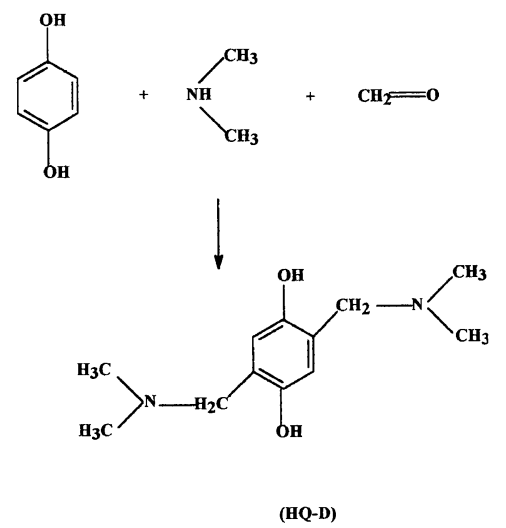

Scheme 1. Synthesis of hydroquinone diamine.

sorption spectrum of this monomer, one $\pi-\pi^{*}$ absorption peak of pure hydroquinone at $310 \mathrm{~nm}$ in $\mathrm{CH}_{3} \mathrm{OH}$, $307 \mathrm{~nm}$ in THF or $304 \mathrm{~nm}$ in DMF was noted. A typical absorption band of the disubstituted benzoquinones with alkyl substituients in the region of $245 \mathrm{~nm}$ is not found. Good spectral agreement between all spectra $\left({ }^{1} \mathrm{H}\right.$ NMR, UV, IR) was observed, and thus confirming the expected structures.

\section{Polymer Synthesis}

2,5-bis- ( $N, N$-dimethylaminomethyl ) -hydroquinone was the desired partner for preparation of some ionenes by two-step Menschutkin synthesis. One synthetic procedure is to use a starting prepolymer with dimethylamino- end groups, a dihalogenated derivative and tertiary diamine, successively. To obtain the first prepolymer, poly(tetramethylene oxide) diol, a diisocyanate with different reactivity of the two isocyanate groups, such as 2,4'-dibenzyldiisocyanate or 2,4toluylene diisocyanate and $N, N$-dimethylaminoethanol were required. Using Menschutkin reaction, the prepolymer was converted to alkylbromide-terminated chains by reaction with 1,4-dibromobutane. Another step involves quaternizing the latter with hydroquinone tertiary diamine to produce polyurethane cationomer with hydroquinone units in polymeric chains (Scheme 2).

As a function of polyether segment length, three polyurethane ionenes (HQ-PUC-1-3) with different concentrations of ionic groups and relative high amounts of hydroquinone units were thus prepared (Table I). In going from polyether of $M_{n}$ : 650 to 2000 , increasing molecular chain length between the urethane and tertiary nitrogen groups, quaternary groups in the polymeric chains decreased from 194.52 at 117.14 mequiv. $\mathrm{Br}^{-} / 100 \mathrm{~g}$ polymer, respectively. The amounts of hydroquinone moieties incorporated into ionomeric backbone were between 10.88 and $6.55 \mathrm{wt} \%$. As companion of HQ-PUC-3, other polycation HQ-PUC-4 (123.87 mequiv. $\mathrm{Br}^{-} / 100 \mathrm{~g}$, hydroquinone $6.94 \mathrm{wt} \%$ ), whose urethane groups were introduced by means of 2,4-TDI, was also synthesized. Elastomeric ionenes as alternating block polymers, are characterized by structures consisting of so-called hardsegments of urethane and polycation type including hydroquinone and polyether soft-segments, as well as hydrogen bonds often formed between urethane groups in the hard-and soft-segments. The main difference in 
Table I. Characteristics of hydroquinone ionenes

\begin{tabular}{|c|c|c|c|c|c|c|c|c|}
\hline \multirow{3}{*}{$\begin{array}{l}\mathrm{PU} \\
\text { Ionene }\end{array}$} & \multicolumn{3}{|c|}{ Mol. weight Diisocyanate } & \multicolumn{3}{|c|}{ Elem. anal. } & \multirow{3}{*}{$\begin{array}{l}\text { Ionic bromine } \\
\text { (mequiv/100 g polymer) }\end{array}$} & \multirow{3}{*}{$\begin{array}{c}\text { HQ } \\
\text { cont. } \\
\frac{\text { a }}{\%}\end{array}$} \\
\hline & PTMO & & & $\mathrm{C}$ & $\mathrm{H}$ & $\mathrm{N}$ & & \\
\hline & $M_{\mathrm{n}}$ & & & \multicolumn{3}{|c|}{$\%$} & & \\
\hline HQ- & & $2,4^{\prime}-$ & Calc. & 55.61 & 7.51 & 5.45 & & \\
\hline PUC-1 & 650 & DBDI & Found: & 55.56 & 7.46 & 5.40 & 194.52 & 10.88 \\
\hline HQ- & & $2,4^{\prime}-$ & Calc. & 57.22 & 8.04 & 4.66 & & \\
\hline PUC-2 & 1000 & DBDI & Found: & 57.16 & 7.97 & 4.60 & 166.21 & 9.30 \\
\hline HQ- & & $2,4^{\prime}-$ & Calc. & 60.0 & 8.94 & 3.29 & & \\
\hline PUC-3 & 2000 & DBDI & Found: & 59.94 & 8.90 & 3.24 & 117.14 & 6.55 \\
\hline HQ- & & $2,4-$ & Calc. & 58.14 & 9.07 & 3.47 & & \\
\hline PUC-4 & 2000 & TDI & Found: & 58.10 & 9.03 & 3.42 & 123.87 & 6.94 \\
\hline
\end{tabular}

${ }^{a}$ Calculated from ionic bromine content.

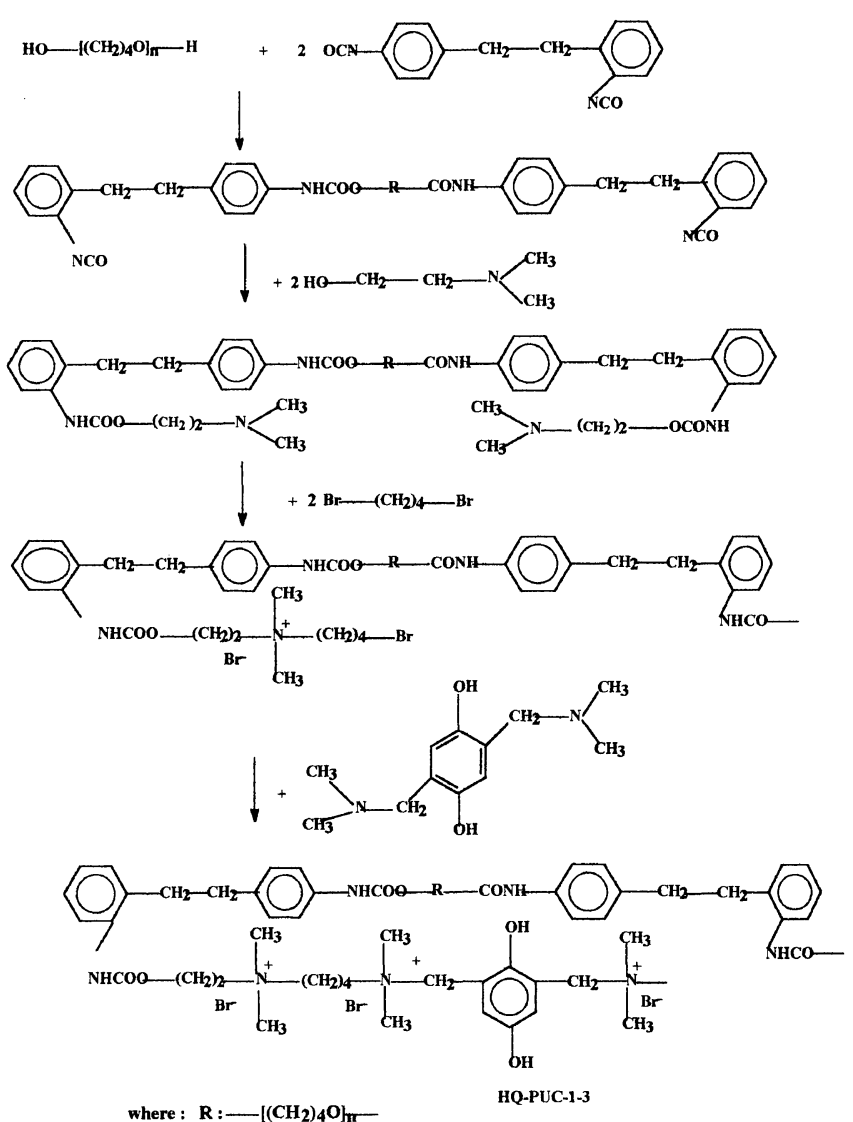

Scheme 2. Synthesis of hydroquinone PU ionenes.

structures of so resulted polyurethane ionenes and other cationomers prepared and studied by our group, ${ }^{22}$ may be related to the presence of hydroquinone structure in the above polycations inserted by tertiary diamine. All polymers are soluble in various solvents, including THF, DMSO, DMF, $\mathrm{CH}_{3} \mathrm{OH}, \mathrm{DMF}: \mathrm{H}_{2} \mathrm{O}$ (4:1 v/v), $\mathrm{CH}_{3} \mathrm{OH}: \mathrm{H}_{2} \mathrm{O}$ $(4: 1 \mathrm{v} / \mathrm{v})$ and form homogeneous solutions that can be processed into good optical quality films.

Hydroquinone ionenes were characterized by elemental analysis. Elemental analysis data suggested good agreement between theoretical values and the present compositions of polymers (Table I). To quantify the extent of quaternizing reaction better, titrimetric determination of ionic bromine content on all polycations was performed. The results showed that the polymers had hydroquinone concentration close to that calculated, indicating that these specific groups were really intro-

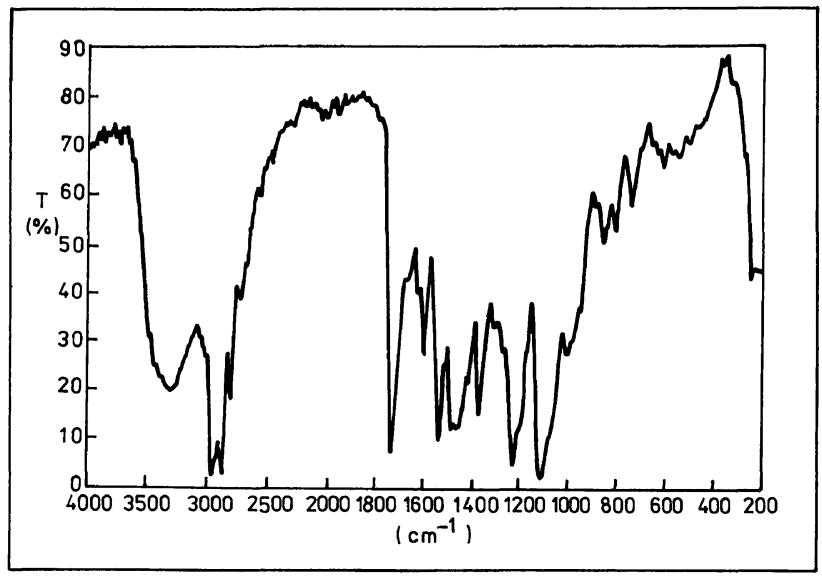

Figure 1. IR spectrum of HQ-PUC-3 polycation in film state.

duced into ionic polyurethanes.

Hydroquinone polymers are white in color, but are susceptible to oxidation by air and moisture and thus become brown in time. ${ }^{23}$ The pale color of ionenes presented earlier, could be reasonable accounted for by assuming that in these cationomers there is a few benzoquinone units, produced by partial oxidation of hydroquinone structure introduced in the initial polymers. Methods for giving meaningful evidence on structural features of these polymers are those based on IR and UV spectroscopy. Therefore, by monitoring the bands characteristic of the hydroquinone and benzoquinone structures it is possible to distinguish chemical groups owing to their specific absorptions, as indication of oxidized and reduced form, present in polymers.

IR spectrum of HQ-PUC-3 (Figure 1) exhibited absorption bands at almost the same positions as the starting prepolymer. Urethane-NH and $\mathrm{CH}_{2}$ asymmetrical stretching vibrations are located at $3320 \mathrm{~cm}^{-1}$ (hydrogen bonded component) and in the $2950,2880 \mathrm{~cm}^{-1}$ regions, respectively. Hydrogen bonded carbonyl stretching band occurred at $1730 \mathrm{~cm}^{-1}$ and the presence of the bonded carbonyl, given by its intensity, is a direct measure of hard domain formation, encountered in classical polyurethanes. Comparison of this spectrum with those of the starting prepolymer, indicated that the ratio of hydrogen bonded carbonyl groups increased as quaternization performed, suggesting emphasized microphase separation in polycations. Common absorptions of $\mathrm{C}-\mathrm{O}-\mathrm{C}$ linkage appeared in the $1220,1130 \mathrm{~cm}^{-1}$ region and those due to the aromatic structure at 1605, 1540, 
870 , and $820 \mathrm{~cm}^{-1}$. Characteristic of the new synthesized polycations is the absorption band from $1480 \mathrm{~cm}^{-1}$, attributed to the hydroquinone structure of the starting monomer and relatively weak vibration positioned at $1670 \mathrm{~cm}^{-1}$, ascribed to carbonyl stretching band of the benzoquinone unit.

The electronic absorption spectra of all polymers measured in THF, showed an absorption maximum at $293 \mathrm{~nm}$ characteristic of the hydroquinone group and two small absorption peaks, one as a shoulder at $245 \mathrm{~nm}$ (observably only at higher dilution), attributed to the disubstituted benzoquinone structure appeared by a partial oxidation of the former and other at $312 \mathrm{~nm}$ (Figure 2 , plot a, curves 1,2 ). To clarify the positions of these peaks, one drop of aqueous solution of $\mathrm{FeCl}_{3}\left(5 \times 10^{-4}\right.$ $\mathrm{m})$, as oxidizing agent was added. In the presence of $\mathrm{Fe}^{+3}$ the hydroquinone groups suffered fast oxidation at benzoquinone form (Figure 2, plot a, curves 3,4). As the percentage of oxidized groups increases, the intensity of the absorptions located at $245 \mathrm{~nm}$ and $312 \mathrm{~nm}$ respectively, increases with decrease of absorption maximum from $293 \mathrm{~nm}$. A new absorption band develops with maximum at $366 \mathrm{~nm}$ and was assigned to the hydroquinone- $\mathrm{Fe}^{+2}$ complex.

Assuming that by irradiation of the benzoquinone structure appeared in polycations is possible to transform it in the starting hydroquinone form, some experiments with irradiation at $365 \mathrm{~nm}$, as representative wavelength of solar emission, were performed. As irradiation of polymer solution in the presence of $\mathrm{Fe}^{+3}$ increased in time ( $5 \mathrm{~min}$ and $10 \mathrm{~min}$ respectively), all maxima decreased gradually with irradiation time (Figure 2, plot $\mathrm{b}$, curves 5,6$)$. Another maximum at $264 \mathrm{~nm}$ was also observed. This new peak in THF: $\mathrm{H}_{2} \mathrm{O}$ polymer solution indicated that during irradiation and in the presence of oxidizing agent, a hydroxybenzoquinone derivative is formed as result of the UV-induced photolitic degradation. ${ }^{24}$ When the same polymer solution was irradiated in the absence of $\mathrm{Fe}^{+3}$, decreasing in maximum at $312 \mathrm{~nm}$ was not followed by significant increasing in absorption peak at $293 \mathrm{~nm}$ (Figure 2, plot b, curve 7), as expected. Such behavior could be explained by reduced concentration of benzoquinone groups in polymeric chain and differences between the molar extinction coefficients of the two structures, UV (THF): $\left(\lambda_{\max }=310 \mathrm{~nm}\right.$, $\varepsilon=4130 \mathrm{M}^{-1} \mathrm{~cm}^{-1} /$ hydroquinone model and $\lambda_{\max }=367$ $\mathrm{nm}, \varepsilon=27000 \mathrm{M}^{-1} \mathrm{~cm}^{-1} /$ aminobenzoquinone. ${ }^{25}$ The spectral evolution of this process indicated that after 2 min of irradiation, the disubstituted benzoquinone groups disappeared in the spectrum, suggesting that reduction of this structure at hydroquinone form is accompanied by photolysis reaction.

Further evidence of two photoprocesses is provided by irradiation of the polycation - $\mathrm{Fe}^{+3}$ solution in the presence of isopropyl alcohol, used as scavenger of $\mathrm{OH}$ radicals, resulted by photolysis of $\mathrm{Fe}^{+3}$ solution (Figure 2, plot $b$, curve 8). In the irradiated mixture, rapid decrease of three absorption maxima located at $366 \mathrm{~nm}$, $312 \mathrm{~nm}$, and $245 \mathrm{~nm}$ with increase of maximum at 264 $\mathrm{nm}$ was measured. In the photolysis reaction, $\mathrm{OH}$ radicals arising from excited $\mathrm{Fe}^{+3}$ were not involved and consequently, the reversibility of the process in aqueous polymer solution could not be proved.

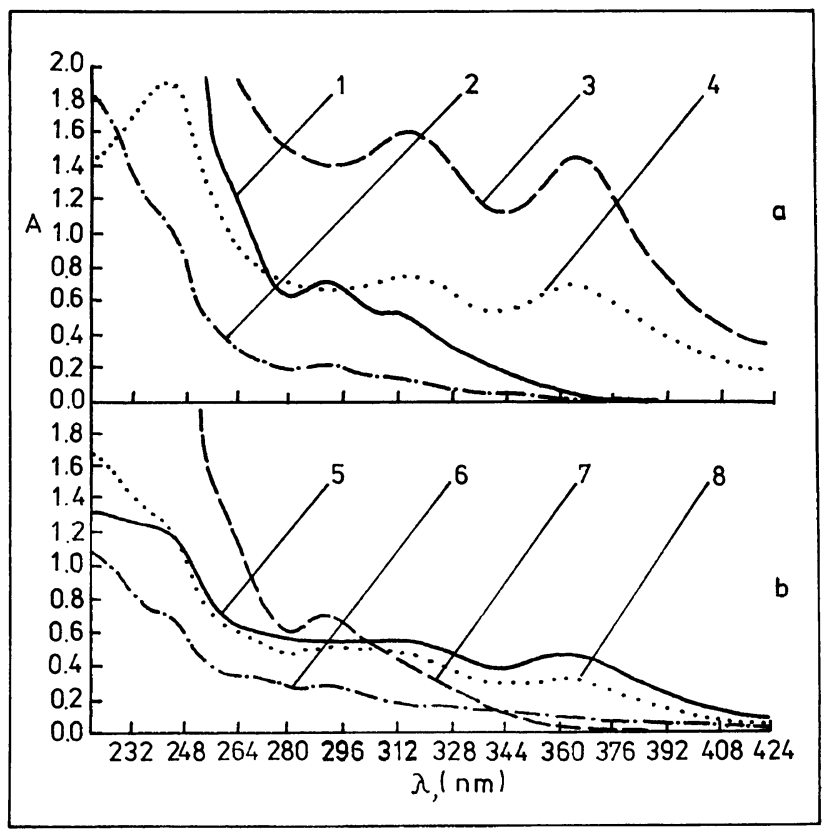

Figure 2. UV spectra of HQ-PUC-3 solution in THF: plot a: 1 (initially); 2 (at higher dilution); 3 (in the presence of $\mathrm{Fe}^{+3}$ ); 4 (in the presence of $\mathrm{Fe}^{+3}$ and at dilution); plot b: 5 (with $\mathrm{Fe}^{+3}$ under 5 min of UV irradiation); 6 (with $\mathrm{Fe}^{+3}$ under 10 min of UV irradiation); 7 (in the absence of $\mathrm{Fe}^{+3}$ and 2 min of UV irradiation) and 8 (with $\mathrm{Fe}^{+3}$ and isopropyl alcohol, irradiated $10 \mathrm{~min}$ ).

Similarities in intensity and positions of the hydroquinone monomer solution in THF subjected to oxidation with $\mathrm{Fe}^{+3}$ and $\mathrm{UV}$ irradiation in the presence of $\mathrm{Fe}^{+3}$ and isopropyl alcohol, supported the early results and confirmed the reasonableness of investigated structures (Figure 3, plots a, b, curves $1-5$ ). Formation of a photolysis product at $232 \mathrm{~nm}$ occurred. In the absence of oxidizing agent, by UV irradiation of the monomer solution in THF (about $20 \mathrm{~min}$ ), the absorption band at $307 \mathrm{~nm}$ remained unchanged in time, as clear indicator of hydroquinone photostability (Figure 3 , plot b, curve 6).

At the same connection, polymeric films were studied by UV spectroscopy (Figure 4). Absorption bands of hydroquinone and benzoquinone groups are positioned about at 293 and $312 \mathrm{~nm}$, respectively. In the film state the intensity of the absorption peak at $312 \mathrm{~nm}$ was higher, as a result of oxidation reaction of the hydroquinone groups during preparing films. Significant increase of this maximum by keeping polymeric films about one year in air, was observed. Under the same UV irradiation conditions, maximum at $312 \mathrm{~nm}$ decreased with irradiation time, until its disappearance after $20 \mathrm{~min}$ of exposure, suggesting that transformation of benzoquinone structure present in a relative small concentration in film occurred. However, the oxidized polycation partially was unstable in sunlight and must be kept in the dark. When the polymeric films were swollen in isopropyl alcohol, as a hydrogen donor, and then irradiated, fast decrease of the maximum at $312 \mathrm{~nm}$ was achieved. In the polymer matrix after about $4 \mathrm{~min}$ of UV irradiation, photoreduction of disubstituted benzoquinone at hydroquinone structure is favored. Therefore, the reversible character of this reaction was evidently only in the case of polymeric films incorporating a hydrogen do- 
E. C. Buruiana and T. Buruiana

Table II. Tensile and thermal properties of hydroquinone ionenes

\begin{tabular}{|c|c|c|c|c|c|c|}
\hline \multirow{3}{*}{$\begin{array}{l}\text { PU } \\
\text { Ionene }^{a}\end{array}$} & \multirow{3}{*}{$\begin{array}{l}\text { Tensile } \\
\text { strength } \\
\mathrm{MPa}\end{array}$} & \multicolumn{2}{|c|}{ Elastic modulus } & \multirow{3}{*}{$\begin{array}{c}\text { Elongation } \\
\frac{\text { at break }}{\%}\end{array}$} & \multicolumn{2}{|c|}{ Soft segment } \\
\hline & & $\mathrm{M}_{100}$ & $\mathrm{M}_{300}$ & & $T_{\mathrm{g}}$ & TGA \\
\hline & & \multicolumn{2}{|c|}{$\mathrm{MPa}$} & & ${ }^{\circ} \mathrm{C}$ & ${ }^{\circ} \mathrm{C}$ \\
\hline $\begin{array}{l}\text { HQ- } \\
\text { PUC-1 }\end{array}$ & 1.21 & 0.82 & 1.08 & 400 & -60 & 195 \\
\hline $\begin{array}{l}\text { HQ- } \\
\text { PUC-2 }\end{array}$ & 1.62 & 1.42 & 1.75 & 550 & -63 & 205 \\
\hline $\begin{array}{l}\text { HQ- } \\
\text { PUC-3 }\end{array}$ & 3.75 & 1.85 & 1.62 & 650 & -54 & 218 \\
\hline $\begin{array}{l}\text { HQ- } \\
\text { PUC-4 }\end{array}$ & 3.54 & 1.32 & 1.20 & 600 & -46 & 198 \\
\hline
\end{tabular}

${ }^{\mathrm{a}}$ Thickness of films $0.2-0.4 \mathrm{~mm}$.

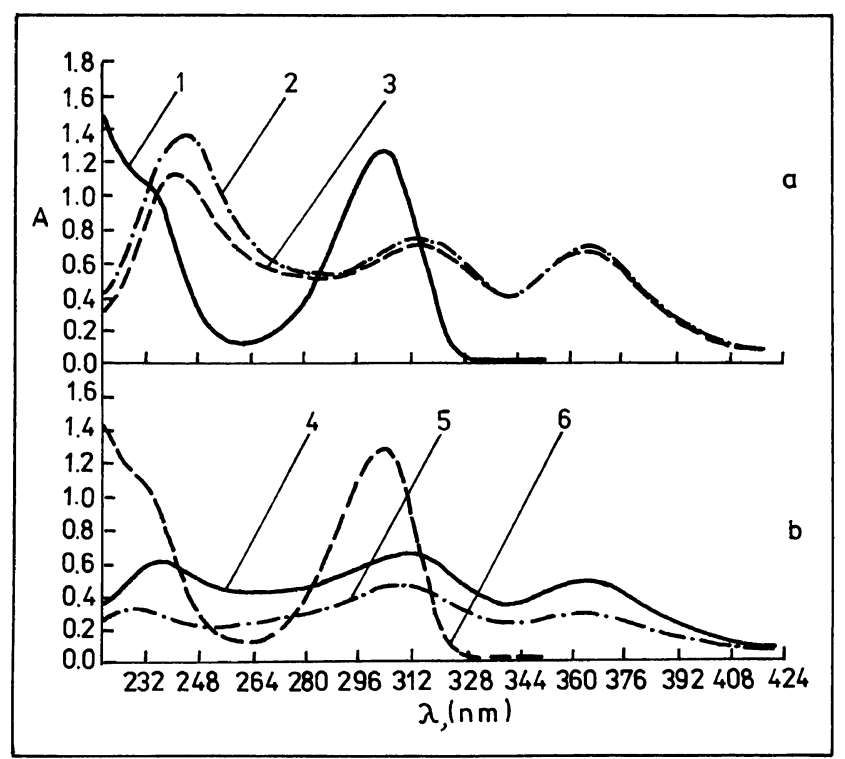

Figure 3. UV spectra of HQ-D monomer in THF: plot a: 1 (initially); 2 (in the presence of $\mathrm{Fe}^{+3}$ ); 3 (with $\mathrm{Fe}^{+3}$ and irradiated 5 $\mathrm{min}$ ); plot b: 4 (with $\mathrm{Fe}^{+3}$ and isopropyl alcohol, irradiated $15 \mathrm{~min}$ ); 5 (with $\mathrm{Fe}^{+3}$ and isopropyl alcohol irradiated $25 \mathrm{~min}$ ) and 6 (in the absence of $\mathrm{Fe}^{+3}$ and 20 min of UV irradiation).

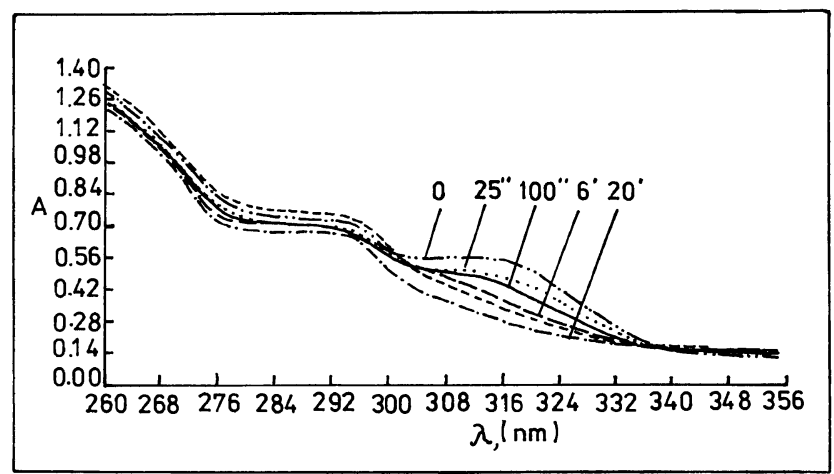

Figure 4. UV spectra of HQ-PUC-3 film subjected to UV irradiation: 0 (initially, -..); $25 \mathrm{~s} \mathrm{(.....);} 100 \mathrm{~s} \mathrm{(-);} 6 \mathrm{~min} \mathrm{(-} \mathrm{-} \mathrm{-);} 20 \mathrm{~min}$ $(\cdot \cdot \cdot \cdot)$; film swelled in isopropyl alcohol and 4 min irradiated (…...).

nor. It may be important to determine the percentage of oxidized groups into ionomeric chains, but there is still not good quantitative predictability of the benzoquinone content at this time, due to the common absorption of polyurethanes in the region of $250 \mathrm{~nm}$.

\section{Some Properties of Hydroquinone Cationomers}

The unique and novel properties of the segmented polyurethanes are interpreted in terms of morphology and physical properties of the block copolymers. Microphase separation between the hard and soft segments, induced by their incompatibility has been noted. ${ }^{26}$ The main difference between a polyurethane and polyurethane ionomer is the structures of the hard segments. In the latter, according to literature data, ${ }^{27}$ various extents of order coexist in the hard segments. The authors made some tensile and thermal measurements of the solutioncast films (Table II). Tensile response of all hydroquinone ionenes indicated that the polymeric films exhibited typical elastomeric quality of the normal polyurethanes, with elongation at break values reaching over $400 \%$. Although the higher content of asymmetrical urethane groups may have significant effect on these properties, the hydroquinone ionenes had acceptable values for this class of polymers, generally recognized for small molecular weights. ${ }^{28}$ Elastic modulus and tensile strength increased with flexible segment length of polyether component as predicted. Two of the four ionenes, HQ-PUC-2 and HQ-PUC-3 showed good strength and flexibility. Such properties should be attributed to increased tendency of the soft segment to crystallize with increasing molecular weight and the hard-segment domains tend to be isolated into soft-segment matrix. Consequently, the formation of hard- and soft-segment rich domains structure, further strengthened by electrostatic interactions between ionic groups may occurrs. There is the possibility that phase separation is enhanced by intermolecular hydrogen bonds of hydroquinone groups within the hard segment domain containing this structure. Comparatively with HQ-PUC-3, an appreciable difference in the tensile properties of $\mathrm{HQ}-\mathrm{PUC}-4$ was not observed, except for modulus values interpreted in terms of starting diisocyanate structure.

DSC analysis of polyurethane ionenes may proved information on phase separation and domain purity in these polycations. DSC thermograms of the conventional polyurethanes exhibit glass transition temperature of soft segments and melting endotherms for hard segments, ${ }^{29}$ as indicator of a less complete microphase separation. For all polyurethane polycations (Table II) containing hydroquinone and ammonium quaternary groups in the hard segments of polymer backbone, only a glass transition temperature $\left(T_{\mathrm{g}}\right)$ in the range $-60^{\circ} \mathrm{C}$ to $-46^{\circ} \mathrm{C}$ (Figure 5) was found. These values can be attributed to the soft segment rich phase $T_{\mathrm{g}}$ greater than that 


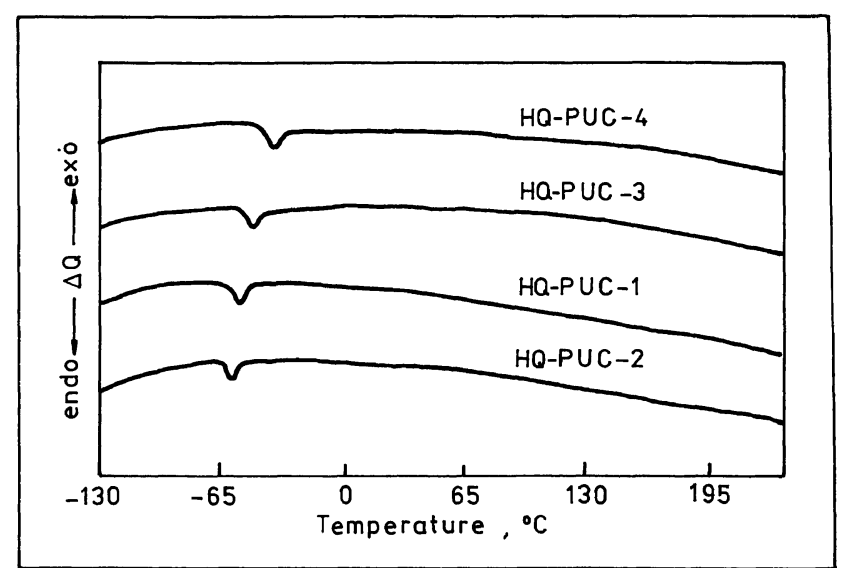

Figure 5. DSC thermograms of the hydroquinone polyurethanes.

of the polyether component (PTMO), ${ }^{30}$ suggestes the presence of certain phase mixing of the two constituent segments. $T_{\mathrm{g}}$ variation is slightly more pronounced at higher content of ionic groups and hydroquinone, as result of enhanced phase separation owing to electrostatic interactions. A study on other elastomeric polyurethane ionenes evidenced two glass transition temperatures (by DMA measurements), one for soft segments and one for hard segments. ${ }^{31}$ Our different results may be explained by the differences between both polymer structures and characterization methods. K. C. Frisch ${ }^{32}$ using DSC analysis determined a single $T_{\mathrm{g}}$ in some polyurethane cationomers. A similar result was also obtained by S. L. Cooper $^{33}$ on cationomers with pendant quaternary groups. Unlike common polyurethanes, in DSC thermograms of hydroquinone ionenes discussed above, high temperature melting endotherms were not observed. A possible cause of this may be the asymmetric structure of 2,4'- or 2,4-isomer in the urethane groups and size of hydroquinone units capable to prevent hard segment crystallization, with major effect on the phase purity. In the synthesis of a hard segment from the typical mixture of the two isomers (2,4-TDI:2,6-TDI / 80:20), a hard segment random structure formed, which substantially inhibits crystallization. Therefore, the absence of crystallization in the hard segments is primarily responsible for imperfect biphasic morphology, where there is mixed hard segments-soft segments and thus a soft or hard segment rich domain structure is conferred to the polymers. This is not surprising since in amorphous polyurethanes often a hard segment $T_{\mathrm{g}}$ is not found and the ionic transitions in DSC thermograms are seldom observed. 27,33

The thermal stability of the hydroquinone polycations was determined by thermogravimetric analysis under nitrogen at a scan rate of $10^{\circ} \mathrm{C} \mathrm{min}{ }^{-1}$. Table II is given the temperature at which the ionenes showed a $5 \%$ weight loss. All polymers (Figure 6) presented a decomposition temperature in the range of 195 and $218^{\circ} \mathrm{C}$, indicating good thermal stability, similar to aminequinone polyurethanes. ${ }^{25}$ Since the hydroquinone cationomers suffered a decomposition at temperatures around $200^{\circ} \mathrm{C}$, this can be an argument for lack of the high temperature endotherms. Supplementary aspects on the quinone polyurethanes with ionomeric character

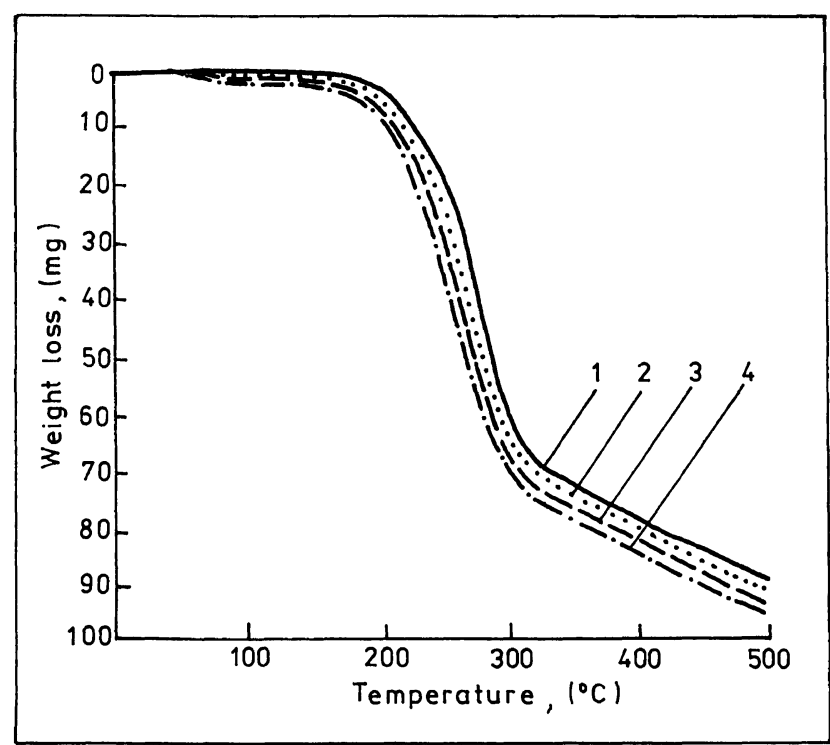

Figure 6. TG curves of polycations: 1 (HQ-PUC-3); 2 (HQ-PUC2); 3 (HQ-PUC-4), and 4 (HQ-PUC-1).

will be studied in our laboratory.

\section{CONCLUSIONS}

Polyetherurethane cationomers with hydroquinone functionality and regularly spaced ionic groups on the macromolecular chain were prepared via a two- step Menschutkin synthesis using as partner 2,5-bis- $(N, N$ dimethylaminomethyl)-hydroquinone. All polymers with a well defined number of hydroquinone groups showed two absorption maxims at $293 \mathrm{~nm}$, characteristic of the hydroquinoid nucleus and at $312 \mathrm{~nm}$, attributed to benzoquinone structure, as a result of partial oxidation of hydroquinone form. In the presence of oxidizing agent $\left(\mathrm{Fe}^{+3}\right)$, a fast oxidation of hydroquinone to benzoquinone groups with absorption at $248 \mathrm{~nm}$, was noted. The oxidized polymers subjected to UV irradiation are unstable and must be kept in the dark. In the polymeric films, the benzoquinone groups can be reduced to hydroquinone state only in the presence of hydrogen donors.

Tensile and thermal properties are similar to those of other elastomeric polyurethanes.

Acknowledgments. The authors acknowledge the support of the Roumanian Academy for financial assistance by GRANT 2714/1998.

\section{REFERENCES}

1. D. H. Evans, in "Encyclopedia of Electrochemistry of the Elements", A. J. Bard, H. Lund, Ed., M. Dekker, New York, N.Y. 1978, Vol. XII, p 1.

2. K. Kaleem, F. Chertok, and S. Erhan, Prog. Org. Coat. 15, 63 (1987).

3. H. Etori, T. Kanbara, and T. Yamamoto, Chem. Lett., 461 (1994).

4. T. Yamamoto and T. Kimura, Macromolecules, 31, 2683 (1998).

5. T. Yamamoto and H. Etori, Macromolecules, 28, 3371 (1995).

6. K. Yamamoto, T. Asada, H. Nishide, and E. Tsuchida, Bull. Chem. Soc. Jpn., 63, 1211 (1990). 
7. P. Wang, B. D. Martin, S. Parida, D. G. Rethwisch, and J. S. Dordick, J. Am. Chem. Soc., 117, 12885 (1995).

8. Q. Zhou and A. Guo, Chin. J. Polym. Sci., 13, 285 (1995).

9. T. Inoue, T. Yamanaka, N. Tabata, and S. Okita, High Perform. Polym., 7, 443 (1995).

10. H. R. Kricheldorf and A. Domschke, Macromolecules, 29, 1337 (1996).

11. J. Liang and D. Nikles, IEEE Trans. Magnetics, 29, 3649 (1993).

12. R. Webb, A. Chacko, and D. Nikles, Polym. Prepr. (Am. Chem. Soc., Div. Polym. Chem.), 35, 769 (1994).

13. D. Nikles, A. Chacko, J. Liang, and R. Webb, J. Polym. Sci. Part A: Polym. Chem., 37, 2339 (1999).

14. L. Zha, M. Wu, and J. Yang, J. Appl. Polym. Sci., 73, 2895 (1999).

15. C. Tonelli, T. Trombetta, and P. Maccone, J. Polym. Sci. Part A: Polym. Chem., 37, 1473 (1999).

16. R. Bagheri and A. R. Jafarpour, Polym. Int., 45, 369 (1998).

17. E. C. Buruiana, T. Buruiana, A. Airinei, G. Robila, and I. Grecu, Polym. J., 31, 510 (1999).

18. T. Buruiana, E. C. Buruiana, A. Airinei, and I. Grecu, Eur. Polym. J., 37, 343 (2000).

19. T. Buruiana, E. C. Buruiana, and A. Airinei, Eur. Polym. J., 33, 877 (1997).

20. T. Buruiana, A. Airinei, E. C. Buruiana, and I. Bestiuc, Angew. Makromol. Chem., 258, 39 (1998).
21. I. Bestiuc, A. Caraculacu, S. Idriceanu, and T. Buruiana, RO Patent, 104788 (Sep. 20, 1994).

22. T. Buruiana, I. Bestiuc, and A. Caraculacu, Angew. Makromol. Chem., 170, 183 (1989).

23. H. G. Cassidy and K. A. Kun in "Encyclopedia Polym. Sci. Techn.”, H. F. Mark, N. G. Gaylord, and N. M. Bikales Ed., John Wiley \& Sons, New York, N.Y., 1966, 5, p 719.

24. P. Mazellier and M. Bolte, J. Photochem. Photobiol. A: Chemistry, 98, 141 (1996).

25. D. Nikles, J. Liang, J. L. Cain, A. P. Chacko, R. Webb, and K. Belmore, J. Polym. Sci. Polym. Chem., Ed., 33, 2881 (1995).

26. J. W. C. V. Bogart, P. E. Gibson, and S. L. Cooper, J. Polym. Sci. Polym. Phys. Ed., 21, 65 (1983)

27. S. A. Chen and W. C. Chan, J. Polym. Sci. Polym. Phys. Ed., 28, 1499 (1990).

28. R. Somoano, S. P. S. Yen, and A. Rembaum, J. Polym. Sci., Part B: Polym. Lett., 8, 467 (1970).

29. C. H. M. Jacques in "Polymer Alloys", D. C. Klempner and K. C. Frisch, Ed., Plenum Press, New York, N.Y., 1977, p 287.

30. J. A. Faucher and J. V. Koleske, Polymer, 9, 44 (1968).

31. M. Watanabe, N. Toneaki, Y. Takizawa, and I. Shinohara, J. Polym. Sci., Part A: Polym. Chem., 20, 2669 (1982).

32. H. A. Al-Salah, H. X. Xiao, J. A. McLean, and K. C. Frisch, J. Polym. Sci., Part A: Polym. Chem., 26, 1609 (1988).

33. R. J. Goddard and S. L. Cooper, J. Polym. Sci. Polym. Phys. Ed., 32, 1557 (1994). 